\title{
Hyers-Ulam stability of functional equations in matrix normed spaces
}

\author{
Jung Rye Lee ${ }^{1}$ Dong Yun Shin ${ }^{2 *}$ and Choonkil Park ${ }^{3}$
}

\footnotetext{
"Correspondence: dyshin@uos.ac.kr ${ }^{2}$ Department of Mathematics, University of Seoul, Seoul, 130-743, Korea

Full list of author information is available at the end of the article
}

\begin{abstract}
In this paper, we prove the Hyers-Ulam stability of the Cauchy additive functional equation and the quadratic functional equation in matrix normed spaces.

MSC: Primary 47L25; 39B82; 46L07; 39B52

Keywords: operator space; Hyers-Ulam stability; Cauchy additive functional equation; quadratic functional equation
\end{abstract}

\section{Introduction and preliminaries}

The abstract characterization given for linear spaces of bounded Hilbert space operators in terms of matricially normed spaces [1] implies that quotients, mapping spaces and various tensor products of operator spaces may again be regarded as operator spaces. Owing in part to this result, the theory of operator spaces is having an increasingly significant effect on operator algebra theory (see [2]).

The proof given in [1] appealed to the theory of ordered operator spaces [3]. Effros and Ruan [4] showed that one can give a purely metric proof of this important theorem by using a technique of Pisier [5] and Haagerup [6] (as modified in [7]).

The stability problem of functional equations originated from a question of Ulam [8] concerning the stability of group homomorphisms.

The functional equation

$$
f(x+y)=f(x)+f(y)
$$

is called the Cauchy additive functional equation. In particular, every solution of the Cauchy additive functional equation is said to be an additive mapping. Hyers [9] gave the first affirmative partial answer to the question of Ulam for Banach spaces. Hyers' theorem was generalized by Aoki [10] for additive mappings and by Rassias [11] for linear mappings by considering an unbounded Cauchy difference. A generalization of the Rassias theorem was obtained by Găvruta [12] by replacing the unbounded Cauchy difference by a general control function in the spirit of Rassias' approach.

In 1990, Rassias [13] during the 27th International Symposium on Functional Equations asked the question whether such a theorem can also be proved for $p \geq 1$. In 1991, Gajda [14] following the same approach as in Rassias [11], gave an affirmative solution to this question for $p>1$. It was shown by Gajda [14] as well as by Rassias and Šemrl [15] that one cannot prove a Rassias-type theorem when $p=1$ ( $c f$. the books of Czerwik [16], Hyers, Isac and Rassias [17]).

(C) 2013 Lee et al.; licensee Springer. This is an Open Access article distributed under the terms of the Creative Commons Attribution License (http://creativecommons.org/licenses/by/2.0), which permits unrestricted use, distribution, and reproduction in any medium, provided the original work is properly cited. 
In 1982, J.M. Rassias [18] followed the innovative approach of Th.M. Rassias' theorem [11] in which he replaced the factor $\|x\|^{p}+\|y\|^{p}$ by $\|x\|^{p} \cdot\|y\|^{q}$ for $p, q \in \mathbb{R}$ with $p+q \neq 1$.

The functional equation

$$
f(x+y)+f(x-y)=2 f(x)+2 f(y)
$$

is called a quadratic functional equation. In particular, every solution of the quadratic functional equation is said to be a quadratic mapping. A Hyers-Ulam stability problem for the quadratic functional equation was proved by Skof [19] for mappings $f: X \rightarrow Y$, where $X$ is a normed space and $Y$ is a Banach space. Cholewa [20] noticed that the theorem of Skof is still true if the relevant domain $X$ is replaced by an Abelian group. Czerwik [21] proved the Hyers-Ulam stability of the quadratic functional equation. The stability problems of several functional equations have been extensively investigated by a number of authors and there are many interesting results concerning this problem (see [22-35]).

We will use the following notations:

$M_{n}(X)$ is the set of all $n \times n$-matrices in $X$;

$e_{j} \in M_{1, n}(\mathbb{C})$ is that $j$ th component is 1 and the other components are zero;

$E_{i j} \in M_{n}(\mathbb{C})$ is that $(i, j)$-component is 1 and the other components are zero;

$E_{i j} \otimes x \in M_{n}(X)$ is that $(i, j)$-component is $x$ and the other components are zero.

For $x \in M_{n}(X), y \in M_{k}(X)$,

$$
x \oplus y=\left(\begin{array}{ll}
x & 0 \\
0 & y
\end{array}\right) .
$$

Let $(X,\|\cdot\|)$ be a normed space. Note that $\left(X,\left\{\|\cdot\|_{n}\right\}\right)$ is a matrix normed space if and only if $\left(M_{n}(X),\|\cdot\|_{n}\right)$ is a normed space for each positive integer $n$ and $\|A x B\|_{k} \leq\|A\|\|B\|\|x\|_{n}$ holds for $A \in M_{k, n}(\mathbb{C}), x=\left(x_{i j}\right) \in M_{n}(X)$ and $B \in M_{n, k}(\mathbb{C})$, and that $\left(X,\left\{\|\cdot\|_{n}\right\}\right)$ is a matrix Banach space if and only if $X$ is a Banach space and $\left(X,\left\{\|\cdot\|_{n}\right\}\right)$ is a matrix normed space.

A matrix normed space $\left(X,\left\{\|\cdot\|_{n}\right\}\right)$ is called an $L^{\infty}$-matrix normed space if $\|x \oplus y\|_{n+k}=$ $\max \left\{\|x\|_{n},\|y\|_{k}\right\}$ holds for all $x \in M_{n}(X)$ and all $y \in M_{k}(X)$.

Let $E, F$ be vector spaces. For a given mapping $h: E \rightarrow F$ and a given positive integer $n$, define $h_{n}: M_{n}(E) \rightarrow M_{n}(F)$ by

$$
h_{n}\left(\left[x_{i j}\right]\right)=\left[h\left(x_{i j}\right)\right]
$$

for all $\left[x_{i j}\right] \in M_{n}(E)$.

Throughout this paper, let $\left(X,\left\{\|\cdot\|_{n}\right\}\right)$ be a matrix normed space and $\left(Y,\left\{\|\cdot\|_{n}\right\}\right)$ be a matrix Banach space.

In Section 2, we prove the Hyers-Ulam stability of the Cauchy additive functional equation in matrix normed spaces. In Section 3, we prove the Hyers-Ulam stability of the quadratic functional equation in matrix normed spaces.

\section{Hyers-Ulam stability of the Cauchy additive functional equation in matrix normed spaces}

In this section, we prove the Hyers-Ulam stability of the Cauchy additive functional equation in matrix normed spaces. 
Lemma 2.1 [36] Let $\left(X,\left\{\|\cdot\|_{n}\right\}\right)$ be a matrix normed space. Then

(1) $\left\|E_{k l} \otimes x\right\|_{n}=\|x\|$ for $x \in X$.

(2) $\left\|x_{k l}\right\| \leq\left\|\left[x_{i j}\right]\right\|_{n} \leq \sum_{i, j=1}^{n}\left\|x_{i j}\right\|$ for $\left[x_{i j}\right] \in M_{n}(X)$.

(3) $\lim _{n \rightarrow \infty} x_{n}=x$ if and only if $\lim _{n \rightarrow \infty} x_{n i j}=x_{i j}$ for $x_{n}=\left[x_{n i j}\right], x=\left[x_{i j}\right] \in M_{k}(X)$.

Proof (1) Since $E_{k l} \otimes x=e_{k}^{*} x e_{l}$ and $\left\|e_{k}^{*}\right\|=\left\|e_{l}\right\|=1,\left\|E_{k l} \otimes x\right\|_{n} \leq\|x\|$. Since $e_{k}\left(E_{k l} \otimes x\right) e_{l}^{*}=x$, $\|x\| \leq\left\|E_{k l} \otimes x\right\|_{n}$. So, $\left\|E_{k l} \otimes x\right\|_{n}=\|x\|$.

(2) Since $e_{k} x e_{l}^{*}=x_{k l}$ and $\left\|e_{k}\right\|=\left\|e_{l}^{*}\right\|=1,\left\|x_{k l}\right\| \leq\left\|\left[x_{i j}\right]\right\|_{n}$.

Since $\left[x_{i j}\right]=\sum_{i, j=1}^{n} E_{i j} \otimes x_{i j}$,

$$
\left\|\left[x_{i j}\right]\right\|_{n}=\left\|\sum_{i, j=1}^{n} E_{i j} \otimes x_{i j}\right\|_{n} \leq \sum_{i, j=1}^{n}\left\|E_{i j} \otimes x_{i j}\right\|_{n}=\sum_{i, j=1}^{n}\left\|x_{i j}\right\| .
$$

(3) By (2), we have

$$
\left\|x_{n k l}-x_{k l}\right\| \leq\left\|\left[x_{n i j}-x_{i j}\right]\right\|_{n}=\left\|\left[x_{n i j}\right]-\left[x_{i j}\right]\right\|_{n} \leq \sum_{i, j=1}^{n}\left\|x_{n i j}-x_{i j}\right\| .
$$

So, we get the result.

For a mapping $f: X \rightarrow Y$, define $D f: X^{2} \rightarrow Y$ and $D f_{n}: M_{n}\left(X^{2}\right) \rightarrow M_{n}(Y)$ by

$$
\begin{aligned}
& D f(a, b)=f(a+b)-f(a)-f(b), \\
& D f_{n}\left(\left[x_{i j}\right],\left[y_{i j}\right]\right):=f_{n}\left(\left[x_{i j}+y_{i j}\right]\right)-f_{n}\left(\left[x_{i j}\right]\right)-f_{n}\left(\left[y_{i j}\right]\right)
\end{aligned}
$$

for all $a, b \in X$ and all $x=\left[x_{i j}\right], y=\left[y_{i j}\right] \in M_{n}(X)$.

Theorem 2.2 Let $f: X \rightarrow Y$ be a mapping and let $\phi: X^{2} \rightarrow[0, \infty)$ be a function such that

$$
\begin{aligned}
& \Phi(a, b):=\frac{1}{2} \sum_{l=0}^{\infty} \frac{1}{2^{l}} \phi\left(2^{l} a, 2^{l} b\right)<+\infty, \\
& \left\|D f_{n}\left(\left[x_{i j}\right],\left[y_{i j}\right]\right)\right\|_{n} \leq \sum_{i, j=1}^{n} \phi\left(x_{i j}, y_{i j}\right)
\end{aligned}
$$

for all $a, b \in X$ and all $x=\left[x_{i j}\right], y=\left[y_{i j}\right] \in M_{n}(X)$. Then there exists a unique additive map$\operatorname{ping} A: X \rightarrow Y$ such that

$$
\left\|f_{n}\left(\left[x_{i j}\right]\right)-A_{n}\left(\left[x_{i j}\right]\right)\right\|_{n} \leq \sum_{i, j=1}^{n} \Phi\left(x_{i j}, x_{i j}\right)
$$

for all $x=\left[x_{i j}\right] \in M_{n}(X)$.

Proof Let $n=1$ in (2.2). Then (2.2) is equivalent to

$$
\|f(a+b)-f(a)-f(b)\| \leq \phi(a, b)
$$


for all $a, b \in X$. By the same reasoning as in [12], there exists a unique additive mapping $A: X \rightarrow Y$ such that

$$
\|f(a)-A(a)\| \leq \Phi(a, a)
$$

for all $a \in X$. The mapping $A: X \rightarrow Y$ is given by

$$
A(a)=\lim _{l \rightarrow \infty} \frac{1}{2^{l}} f\left(2^{l} a\right)
$$

for all $a \in X$. By Lemma 2.1,

$$
\left\|f_{n}\left(\left[x_{i j}\right]\right)-A_{n}\left(\left[x_{i j}\right]\right)\right\|_{n} \leq \sum_{i, j=1}^{n}\left\|f\left(x_{i j}\right)-A\left(x_{i j}\right)\right\| \leq \sum_{i, j=1}^{n} \Phi\left(x_{i j}, x_{i j}\right)
$$

for all $x=\left[x_{i j}\right] \in M_{n}(X)$. Thus, $A: X \rightarrow Y$ is a unique additive mapping satisfying (2.3), as desired.

Corollary 2.3 Let $r, \theta$ be positive real numbers with $r<1$. Let $f: X \rightarrow Y$ be a mapping such that

$$
\left\|D f_{n}\left(\left[x_{i j}\right],\left[y_{i j}\right]\right)\right\|_{n} \leq \sum_{i, j=1}^{n} \theta\left(\left\|x_{i j}\right\|^{r}+\left\|y_{i j}\right\|^{r}\right)
$$

for all $x=\left[x_{i j}\right], y=\left[y_{i j}\right] \in M_{n}(X)$. Then there exists a unique additive mapping $A: X \rightarrow Y$ such that

$$
\left\|f_{n}\left(\left[x_{i j}\right]\right)-A_{n}\left(\left[x_{i j}\right]\right)\right\|_{n} \leq \sum_{i, j=1}^{n} \frac{2 \theta}{2-2^{r}}\left\|x_{i j}\right\|^{r}
$$

for all $x=\left[x_{i j}\right] \in M_{n}(X)$.

Proof Letting $\phi(a, b)=\theta\left(\|a\|^{r}+\|b\|^{r}\right)$ in Theorem 2.2, we obtain the result.

Theorem 2.4 Let $f: X \rightarrow Y$ be a mapping and let $\phi: X^{2} \rightarrow[0, \infty)$ be a function satisfying (2.2) and

$$
\Phi(a, b):=\frac{1}{2} \sum_{l=1}^{\infty} 2^{l} \phi\left(\frac{a}{2^{l}}, \frac{b}{2^{l}}\right)<+\infty
$$

for all $a, b \in X$. Then there exists a unique additive mapping $A: X \rightarrow Y$ such that

$$
\left\|f_{n}\left(\left[x_{i j}\right]\right)-A_{n}\left(\left[x_{i j}\right]\right)\right\|_{n} \leq \sum_{i, j=1}^{n} \Phi\left(x_{i j}, x_{i j}\right)
$$

for all $x=\left[x_{i j}\right] \in M_{n}(X)$.

Proof The proof is similar to the proof of Theorem 2.2. 
Corollary 2.5 Let $r, \theta$ be positive real numbers with $r>1$. Let $f: X \rightarrow Y$ be a mapping satisfying (2.4). Then there exists a unique additive mapping $A: X \rightarrow Y$ such that

$$
\left\|f_{n}\left(\left[x_{i j}\right]\right)-A_{n}\left(\left[x_{i j}\right]\right)\right\|_{n} \leq \sum_{i, j=1}^{n} \frac{2 \theta}{2^{r}-2}\left\|x_{i j}\right\|^{r}
$$

for all $x=\left[x_{i j}\right] \in M_{n}(X)$.

Proof Letting $\phi(a, b)=\theta\left(\|a\|^{r}+\|b\|^{r}\right)$ in Theorem 2.4, we obtain the result.

We need the following result.

Lemma 2.6 [37] If $E$ is an $L^{\infty}$-matrix normed space, then $\left\|\left[x_{i j}\right]\right\|_{n} \leq\left\|\left[\left\|x_{i j}\right\|\right]\right\|_{n}$ for all $\left[x_{i j}\right] \in$ $M_{n}(E)$.

Theorem 2.7 Let $Y$ be an $L^{\infty}$-normed Banach space. Let $f: X \rightarrow Y$ be a mapping and let $\phi: X^{2} \rightarrow[0, \infty)$ be a function satisfying $(2.1)$ and

$$
\left\|D f_{n}\left(\left[x_{i j}\right],\left[y_{i j}\right]\right)\right\|_{n} \leq\left\|\left[\phi\left(x_{i j}, y_{i j}\right)\right]\right\|_{n}
$$

for all $x=\left[x_{i j}\right], y=\left[y_{i j}\right] \in M_{n}(X)$. Then there exists a unique additive mapping $A: X \rightarrow Y$ such that

$$
\left\|\left[f\left(x_{i j}\right)-A\left(x_{i j}\right)\right]\right\|_{n} \leq\left\|\left[\Phi\left(x_{i j}, x_{i j}\right)\right]\right\|_{n}
$$

for all $x=\left[x_{i j}\right] \in M_{n}(X)$. Here $\Phi$ is given in Theorem 2.2.

Proof By the same reasoning as in the proof of Theorem 2.2, there exists a unique additive mapping $A: X \rightarrow Y$ such that

$$
\|f(a)-A(a)\| \leq \Phi(a, a)
$$

for all $a \in X$. The mapping $A: X \rightarrow Y$ is given by

$$
A(a)=\lim _{l \rightarrow \infty} \frac{1}{2^{l}} f\left(2^{l} a\right)
$$

for all $a \in X$.

It is easy to show that if $0 \leq a_{i j} \leq b_{i j}$ for all $i, j$, then

$$
\left\|\left[a_{i j}\right]\right\|_{n} \leq\left\|\left[b_{i j}\right]\right\|_{n} .
$$

By Lemma 2.6 and (2.8),

$$
\left\|\left[f\left(x_{i j}\right)-A\left(x_{i j}\right)\right]\right\|_{n} \leq\left\|\left[\left\|f\left(x_{i j}\right)-A\left(x_{i j}\right)\right\|\right]\right\|_{n} \leq\left\|\left[\Phi\left(x_{i j}, x_{i j}\right)\right]\right\|_{n}
$$

for all $x=\left[x_{i j}\right] \in M_{n}(X)$. So, we obtain the inequality (2.7). 
Corollary 2.8 Let $Y$ be an $L^{\infty}$-normed Banach space. Let $r, \theta$ be positive real numbers with $r<1$. Let $f: X \rightarrow Y$ be a mapping such that

$$
\left\|D f_{n}\left(\left[x_{i j}\right],\left[y_{i j}\right]\right)\right\|_{n} \leq\left\|\left[\theta\left(\left\|x_{i j}\right\|^{r}+\left\|y_{i j}\right\|^{r}\right)\right]\right\|_{n}
$$

for all $x=\left[x_{i j}\right], y=\left[y_{i j}\right] \in M_{n}(X)$. Then there exists a unique additive mapping $A: X \rightarrow Y$ such that

$$
\left\|f_{n}\left(\left[x_{i j}\right]\right)-A_{n}\left(\left[x_{i j}\right]\right)\right\|_{n} \leq\left\|\left[\frac{2 \theta}{2-2^{r}}\left\|x_{i j}\right\|^{r}\right]\right\|_{n}
$$

for all $x=\left[x_{i j}\right] \in M_{n}(X)$.

Proof Letting $\phi(a, b)=\theta\left(\|a\|^{r}+\|b\|^{r}\right)$ in Theorem 2.7, we obtain the result.

Theorem 2.9 Let $Y$ be an $L^{\infty}$-normed Banach space. Let $f: X \rightarrow Y$ be a mapping and let $\phi: X^{2} \rightarrow[0, \infty)$ be a function satisfying (2.5) and (2.6). Then there exists a unique additive mapping $A: X \rightarrow Y$ such that

$$
\left\|\left[f\left(x_{i j}\right)-A\left(x_{i j}\right)\right]\right\|_{n} \leq\left\|\left[\Phi\left(x_{i j}, x_{i j}\right)\right]\right\|_{n}
$$

for all $x=\left[x_{i j}\right] \in M_{n}(X)$. Here $\Phi$ is given in Theorem 2.4.

Proof The proof is similar to the proof of Theorem 2.7.

Corollary 2.10 Let $Y$ be an $L^{\infty}$-normed Banach space. Let $r, \theta$ be positive real numbers with $r>1$. Let $f: X \rightarrow Y$ be a mapping satisfying (2.9). Then there exists a unique additive mapping $A: X \rightarrow Y$ such that

$$
\left\|f_{n}\left(\left[x_{i j}\right]\right)-A_{n}\left(\left[x_{i j}\right]\right)\right\|_{n} \leq\left\|\left[\frac{2 \theta}{2^{r}-2}\left\|x_{i j}\right\|^{r}\right]\right\|_{n}
$$

for all $x=\left[x_{i j}\right] \in M_{n}(X)$.

Proof Letting $\phi(a, b)=\theta\left(\|a\|^{r}+\|b\|^{r}\right)$ in Theorem 2.9, we obtain the result.

\section{Hyers-Ulam stability of the quadratic functional equation in matrix normed spaces}

In this section, we prove the Hyers-Ulam stability of the quadratic functional equation in matrix normed spaces.

For a mapping $f: X \rightarrow Y$, define $D f: X^{2} \rightarrow Y$ and $D f_{n}: M_{n}\left(X^{2}\right) \rightarrow M_{n}(Y)$ by

$$
\begin{aligned}
& D f(a, b)=f(a+b)+f(a-b)-2 f(a)-2 f(b), \\
& D f_{n}\left(\left[x_{i j}\right],\left[y_{i j}\right]\right):=f_{n}\left(\left[x_{i j}+y_{i j}\right]\right)+f_{n}\left(\left[x_{i j}-y_{i j}\right]\right)-2 f_{n}\left(\left[x_{i j}\right]\right)-2 f_{n}\left(\left[y_{i j}\right]\right)
\end{aligned}
$$

for all $a, b \in X$ and all $x=\left[x_{i j}\right], y=\left[y_{i j}\right] \in M_{n}(X)$. 
Theorem 3.1 Let $f: X \rightarrow Y$ be a mapping and let $\phi: X^{2} \rightarrow[0, \infty)$ be a function such that

$$
\begin{aligned}
& \Phi(a, b):=\frac{1}{4} \sum_{l=0}^{\infty} \frac{1}{4^{l}} \phi\left(2^{l} a, 2^{l} b\right)<+\infty, \\
& \left\|D f_{n}\left(\left[x_{i j}\right],\left[y_{i j}\right]\right)\right\|_{n} \leq \sum_{i, j=1}^{n} \phi\left(x_{i j}, y_{i j}\right)
\end{aligned}
$$

for all $a, b \in X$ and all $x=\left[x_{i j}\right], y=\left[y_{i j}\right] \in M_{n}(X)$. Then there exists a unique quadratic mapping $Q: X \rightarrow Y$ such that

$$
\left\|f_{n}\left(\left[x_{i j}\right]\right)-Q_{n}\left(\left[x_{i j}\right]\right)\right\|_{n} \leq \sum_{i, j=1}^{n} \Phi\left(x_{i j}, x_{i j}\right)
$$

for all $x=\left[x_{i j}\right] \in M_{n}(X)$.

Proof Let $n=1$ in (3.2). Then (3.2) is equivalent to

$$
\|f(a+b)+f(a-b)-2 f(a)-2 f(b)\| \leq \phi(a, b)
$$

for all $a, b \in X$. By the same reasoning as in [21], there exists a unique quadratic mapping $Q: X \rightarrow Y$ such that

$$
\|f(a)-Q(a)\| \leq \Phi(a, a)
$$

for all $a \in X$. The mapping $Q: X \rightarrow Y$ is given by

$$
Q(a)=\lim _{l \rightarrow \infty} \frac{1}{4^{l}} f\left(2^{l} a\right)
$$

for all $a \in X$.

By Lemma 2.1,

$$
\begin{aligned}
\left\|f_{n}\left(\left[x_{i j}\right]\right)-Q_{n}\left(\left[x_{i j}\right]\right)\right\|_{n} & \leq \sum_{i, j=1}^{n}\left\|f\left(x_{i j}\right)-Q\left(x_{i j}\right)\right\| \\
& \leq \sum_{i, j=1}^{n} \Phi\left(x_{i j}, x_{i j}\right)
\end{aligned}
$$

for all $x=\left[x_{i j}\right] \in M_{n}(X)$. Thus, $Q: X \rightarrow Y$ is a unique quadratic mapping satisfying (3.3), as desired.

Corollary 3.2 Let $r, \theta$ be positive real numbers with $r<2$. Let $f: X \rightarrow Y$ be a mapping such that

$$
\left\|D f_{n}\left(\left[x_{i j}\right],\left[y_{i j}\right]\right)\right\|_{n} \leq \sum_{i, j=1}^{n} \theta\left(\left\|x_{i j}\right\|^{r}+\left\|y_{i j}\right\|^{r}\right)
$$


for all $x=\left[x_{i j}\right], y=\left[y_{i j}\right] \in M_{n}(X)$. Then there exists a unique quadratic mapping $Q: X \rightarrow Y$ such that

$$
\left\|f_{n}\left(\left[x_{i j}\right]\right)-Q_{n}\left(\left[x_{i j}\right]\right)\right\|_{n} \leq \sum_{i, j=1}^{n} \frac{2 \theta}{4-2^{r}}\left\|x_{i j}\right\|^{r}
$$

for all $x=\left[x_{i j}\right] \in M_{n}(X)$.

Proof Letting $\phi(a, b)=\theta\left(\|a\|^{r}+\|b\|^{r}\right)$ in Theorem 3.1, we obtain the result.

Theorem 3.3 Letf $: X \rightarrow Y$ be a mapping and let $\phi: X^{2} \rightarrow[0, \infty)$ be a function satisfying (3.2) and

$$
\Phi(a, b):=\frac{1}{4} \sum_{l=1}^{\infty} 4^{l} \phi\left(\frac{a}{2^{l}}, \frac{b}{2^{l}}\right)<+\infty
$$

for all $a, b \in X$. Then there exists a unique quadratic mapping $Q: X \rightarrow Y$ such that

$$
\left\|f_{n}\left(\left[x_{i j}\right]\right)-Q_{n}\left(\left[x_{i j}\right]\right)\right\|_{n} \leq \sum_{i, j=1}^{n} \Phi\left(x_{i j}, x_{i j}\right)
$$

for all $x=\left[x_{i j}\right] \in M_{n}(X)$.

Proof The proof is similar to the proof of Theorem 3.1.

Corollary 3.4 Let $r, \theta$ be positive real numbers with $r>2$. Let $f: X \rightarrow Y$ be a mapping satisfying (3.4). Then there exists a unique quadratic mapping $Q: X \rightarrow Y$ such that

$$
\left\|f_{n}\left(\left[x_{i j}\right]\right)-Q_{n}\left(\left[x_{i j}\right]\right)\right\|_{n} \leq \sum_{i, j=1}^{n} \frac{2 \theta}{2^{r}-4}\left\|x_{i j}\right\|^{r}
$$

for all $x=\left[x_{i j}\right] \in M_{n}(X)$.

Proof Letting $\phi(a, b)=\theta\left(\|a\|^{r}+\|b\|^{r}\right)$ in Theorem 3.3, we obtain the result.

From now on, assume that $Y$ is an $L^{\infty}$-normed Banach space.

Theorem 3.5 Let $f: X \rightarrow Y$ be a mapping and let $\phi: X^{2} \rightarrow[0, \infty)$ be a function satisfying (3.1) and

$$
\left\|D f_{n}\left(\left[x_{i j}\right],\left[y_{i j}\right]\right)\right\|_{n} \leq\left\|\left[\phi\left(x_{i j}, y_{i j}\right)\right]\right\|_{n}
$$

for all $x=\left[x_{i j}\right], y=\left[y_{i j}\right] \in M_{n}(X)$. Then there exists a unique quadratic mapping $Q: X \rightarrow Y$ such that

$$
\left\|\left[f\left(x_{i j}\right)-Q\left(x_{i j}\right)\right]\right\|_{n} \leq\left\|\left[\Phi\left(x_{i j}, x_{i j}\right)\right]\right\|_{n}
$$

for all $x=\left[x_{i j}\right] \in M_{n}(X)$. Here $\Phi$ is given in Theorem 3.1. 
Proof By the same reasoning as in the proof of Theorem 3.1, there exists a unique quadratic mapping $Q: X \rightarrow Y$ such that

$$
\|f(a)-Q(a)\| \leq \Phi(a, a)
$$

for all $a \in X$. The mapping $Q: X \rightarrow Y$ is given by

$$
Q(a)=\lim _{l \rightarrow \infty} \frac{1}{4^{l}} f\left(2^{l} a\right)
$$

for all $a \in X$. By Lemma 2.6 and (2.8),

$$
\left\|\left[f\left(x_{i j}\right)-Q\left(x_{i j}\right)\right]\right\|_{n} \leq\left\|\left[\left\|f\left(x_{i j}\right)-Q\left(x_{i j}\right)\right\|\right]\right\|_{n} \leq\left\|\left[\Phi\left(x_{i j}, x_{i j}\right)\right]\right\|_{n}
$$

for all $x=\left[x_{i j}\right] \in M_{n}(X)$. So, we obtain the inequality (3.7).

Corollary 3.6 Let $r, \theta$ be positive real numbers with $r<2$. Let $f: X \rightarrow Y$ be a mapping such that

$$
\left\|D f_{n}\left(\left[x_{i j}\right],\left[y_{i j}\right]\right)\right\|_{n} \leq\left\|\left[\theta\left(\left\|x_{i j}\right\|^{r}+\left\|y_{i j}\right\|^{r}\right)\right]\right\|_{n}
$$

for all $x=\left[x_{i j}\right], y=\left[y_{i j}\right] \in M_{n}(X)$. Then there exists a unique quadratic mapping $Q: X \rightarrow Y$ such that

$$
\left\|f_{n}\left(\left[x_{i j}\right]\right)-Q_{n}\left(\left[x_{i j}\right]\right)\right\|_{n} \leq\left\|\left[\frac{2 \theta}{4-2^{r}}\left\|x_{i j}\right\|^{r}\right]\right\|_{n}
$$

for all $x=\left[x_{i j}\right] \in M_{n}(X)$.

Proof Letting $\phi(a, b)=\theta\left(\|a\|^{r}+\|b\|^{r}\right)$ in Theorem 3.5, we obtain the result.

Theorem 3.7 Let $f: X \rightarrow Y$ be a mapping and let $\phi: X^{2} \rightarrow[0, \infty)$ be a function satisfying (3.5) and (3.6). Then there exists a unique quadratic mapping $Q: X \rightarrow Y$ such that

$$
\left\|\left[f\left(x_{i j}\right)-Q\left(x_{i j}\right)\right]\right\|_{n} \leq\left\|\left[\Phi\left(x_{i j}, x_{i j}\right)\right]\right\|_{n}
$$

for all $x=\left[x_{i j}\right] \in M_{n}(X)$. Here $\Phi$ is given in Theorem 3.3.

Proof The proof is similar to the proof of Theorem 3.5.

Corollary 3.8 Let $r, \theta$ be positive real numbers with $r>2$. Let $f: X \rightarrow Y$ be a mapping satisfying (3.8). Then there exists a unique quadratic mapping $Q: X \rightarrow Y$ such that

$$
\left\|f_{n}\left(\left[x_{i j}\right]\right)-Q_{n}\left(\left[x_{i j}\right]\right)\right\|_{n} \leq\left\|\left[\frac{2 \theta}{2^{r}-4}\left\|x_{i j}\right\|^{r}\right]\right\|_{n}
$$

for all $x=\left[x_{i j}\right] \in M_{n}(X)$.

Proof Letting $\phi(a, b)=\theta\left(\|a\|^{r}+\|b\|^{r}\right)$ in Theorem 3.7, we obtain the result. 


\section{Competing interests}

The authors declare that they have no competing interests.

\section{Authors' contributions}

All authors conceived of the study, participated in its design and coordination, drafted the manuscript, participated in the sequence alignment, and read and approved the final manuscript.

\section{Author details}

${ }^{1}$ Department of Mathematics, Daejin University, Pocheon, Kyeonggi 487-711, Korea. ${ }^{2}$ Department of Mathematics, University of Seoul, Seoul, 130-743, Korea. ${ }^{3}$ Department of Mathematics, Research Institute for Natural Sciences, Hanyang University, Seoul, 133-791, Korea.

\section{Acknowledgements}

D.Y. Shin was supported by the Basic Science Research Program through the National Research Foundation of Korea funded by the Ministry of Education, Science and Technology (NRF-2010-0021792), and C. Park was supported by the Basic Science Research Program through the National Research Foundation of Korea funded by the Ministry of Education, Science and Technology (NRF-2012R1A1A2004299).

\section{Received: 13 August 2012 Accepted: 21 December 2012 Published: 16 January 2013}

\section{References}

1. Ruan, ZJ: Subspaces of $C^{*}$-algebras. J. Funct. Anal. 76, 217-230 (1988)

2. Effros, E, Ruan, ZJ: On approximation properties for operator spaces. Int. J. Math. 1, 163-187 (1990)

3. Choi, MD, Effros, E: Injectivity and operator spaces. J. Funct. Anal. 24, 156-209 (1977)

4. Effros, E, Ruan, ZJ: On the abstract characterization of operator spaces. Proc. Am. Math. Soc. 119, $579-584$ (1993)

5. Pisier, G: Grothendieck's theorem for non-commutative $C^{*}$-algebras with an appendix on Grothendieck's constants. J. Funct. Anal. 29, 397-415 (1978)

6. Haagerup, U: Decomp. of completely bounded maps (unpublished manuscript)

7. Effros, E: On Multilinear Completely Bounded Module Maps. Contemp. Math., vol. 62, pp. 479-501. Am. Math. Soc Providence (1987)

8. Ulam, SM: A Collection of the Mathematical Problems. Interscience, New York (1960)

9. Hyers, DH: On the stability of the linear functional equation. Proc. Natl. Acad. Sci. USA 27, $222-224$ (1941)

10. Aoki, T: On the stability of the linear transformation in Banach spaces. J. Math. Soc. Jpn. 2, 64-66 (1950)

11. Rassias, TM: On the stability of the linear mapping in Banach spaces. Proc. Am. Math. Soc. 72, 297-300 (1978)

12. Găvruta, P: A generalization of the Hyers-Ulam-Rassias stability of approximately additive mappings. J. Math. Anal. Appl. 184, 431-436 (1994)

13. Rassias, TM: Problem 16; 2. Report of the 27th International Symp. on Functional Equations. Aequ. Math. 39, 292-293; 309 (1990)

14. Gajda, Z: On stability of additive mappings. Int. J. Math. Math. Sci. 14, 431-434 (1991)

15. Rassias, TM, Šemrl, P: On the behaviour of mappings which do not satisfy Hyers-Ulam stability. Proc. Am. Math. Soc. 114, 989-993 (1992)

16. Czerwik, P: Functional Equations and Inequalities in Several Variables. World Scientific, Singapore (2002)

17. Hyers, DH, Isac, G, Rassias, TM: Stability of Functional Equations in Several Variables. Birkhäuser, Basel (1998)

18. Rassias, JM: On approximation of approximately linear mappings by linear mappings. J. Funct. Anal. 46, 126-130 (1982)

19. Skof, F: Proprietà locali e approssimazione di operatori. Rend. Semin. Mat. Fis. Milano 53, 113-129 (1983)

20. Cholewa, PW: Remarks on the stability of functional equations. Aequ. Math. 27, 76-86 (1984)

21. Czerwik, S: On the stability of the quadratic mapping in normed spaces. Abh. Math. Semin. Univ. Hamb. 62, 59-64 (1992)

22. Aczel, J, Dhombres, J: Functional Equations in Several Variables. Cambridge University Press, Cambridge (1989)

23. Najati, A, Park, C: The Pexiderized Apollonius-Jensen type additive mapping and isomorphisms between $C^{*}$-algebras. J. Differ. Equ. Appl. 14, 459-479 (2008)

24. Najati, A, Park, C: On the stability of an $n$-dimensional functional equation originating from quadratic forms. Taiwan. J. Math. 12, 1609-1624 (2008)

25. Najati, A, Park, C: Fixed points and stability of a generalized quadratic functional equation. J. Inequal. Appl. 2009 Article ID 193035 (2009)

26. Najati, A, Rassias, TM: Stability of a mixed functional equation in several variables on Banach modules. Nonlinear Anal. TMA 72, 1755-1767 (2010)

27. Eshaghi Gordji, M, Savadkouhi, MB: Stability of a mixed type cubic-quartic functional equation in non-Archimedean spaces. Appl. Math. Lett. 23, 1198-1202 (2010)

28. Isac, G, Rassias, TM: On the Hyers-Ulam stability of $\psi$-additive mappings. J. Approx. Theory 72, $131-137$ (1993)

29. Jun, K, Lee, Y: A generalization of the Hyers-Ulam-Rassias stability of the Pexiderized quadratic equations. J. Math. Anal. Appl. 297, 70-86 (2004)

30. Jung, S: Hyers-Ulam-Rassias Stability of Functional Equations in Mathematical Analysis. Hadronic Press, Palm Harbor (2001)

31. Park, C: Homomorphisms between Poisson JC*-algebras. Bull. Braz. Math. Soc. 36, 79-97 (2005)

32. Rassias, JM: Solution of a problem of Ulam. J. Approx. Theory 57, 268-273 (1989)

33. Rassias, TM (ed.): Functional Equations and Inequalities. Kluwer Academic, Dordrecht (2000)

34. Rassias, TM: On the stability of functional equations in Banach spaces. J. Math. Anal. Appl. 251, 264-284 (2000)

35. Rassias, TM: On the stability of functional equations and a problem of Ulam. Acta Math. Appl. 62, 23-130 (2000)

36. Effros, E, Ruan, ZJ: On matricially normed spaces. Pac. J. Math. 132, 243-264 (1988)

37. Shin, D, Lee, S, Byun, C, Kim, S: On matrix normed spaces. Bull. Korean Math. Soc. 27, 103-112 (1983) 
doi:10.1186/1029-242X-2013-22

Cite this article as: Lee et al.: Hyers-Ulam stability of functional equations in matrix normed spaces. Journal of Inequalities and Applications 2013 2013:22.

Submit your manuscript to a SpringerOpen ${ }^{\circ}$ journal and benefit from:

- Convenient online submission

- Rigorous peer review

- Immediate publication on acceptance

- Open access: articles freely available online

- High visibility within the field

- Retaining the copyright to your article

Submit your next manuscript at $\gg$ springeropen.com 